\title{
Adaptação do jogo Bingo como proposta de ideação no processo de geração de alternativas de design
}

\section{Adaptation of the Bingo game as an ideation proposal in the design alternatives process generating}

\author{
Jason Scalco Piloti, Universidade Federal do Rio Grande do Sul. \\ jason.piloti@ufrgs.br
}

\author{
Camila Vieira Ghisleni, Universidade Federal do Rio Grande do Sul. \\ camila.ghisleni@ufrgs.br
}

Fabiano Scherer, Universidade Federal do Rio Grande do Sul.

fabiano.scherer@ufrgs.br

\begin{abstract}
Resumo
A fase de ideação, no processo de design de novos produtos/serviços, compreende a geração de diferentes ideias ou soluções para um determinado problema. Ela pode contar com o apoio de ferramentas e técnicas que possibilitam aumentar o potencial de inovação das soluções, apoiando, assim, os designers em suas inspirações. Nesse contexto, este estudo apresenta a adaptação do clássico jogo Bingo à técnica de ideação Ideation Game e ao método TRIZ (Teoria da Resolução Inventiva de Problemas), como ferramentas facilitadoras na geração de novas ideias. A atividade foi aplicada com alunos de mestrado e doutorado do Programa de Pós-Graduação em Design da Universidade Federal do Rio Grande do Sul (PGDesign/UFRGS). A partir dos conjuntos de ideias gerados por cada grupo, pode-se observar que as rodadas de bingo auxiliaram tanto no estímulo de diferentes níveis de criatividade quanto nas soluções para as alternativas de projeto. Cabe ressaltar que os resultados demonstraram que a ferramenta proposta promoveu também o engajamento entre os participantes de forma lúdica e divertida, apesar de apresentar algumas limitações quanto sua aplicação.
\end{abstract}

Palavras-chave: Processo Criativo; Geração de Ideias; Jogo de Ideação; Ferramentas de Design

\begin{abstract}
The ideation is a stage in design process of new products/services that involves the generation of different ideas or solutions for a given problem. By the tools and techniques that increase the potential of innovation solutions', the ideation provides support designers in their inspirations. In this context, this study presents the adaptation of the classic game Bingo to an ideation method, the Ideation Game, together with the TRIZ (Theory of Inventive Problem Solving) method as a tool for generating new ideas. The method was applied to masters and doctoral students, from the Postgraduate Program in Design of the Federal University of Rio Grande do Sul (PGDesign/UFRGS). From the sets of ideas generated by each group, we understand that the Ideation Game, through the bingo rounds, helped as one different stimulus levels of creativity, as the solutions for the design alternatives. It is worth mentioning that the results showed that the proposed tool promoted engagement among the participants in a playful and fun way, despite presenting some limitations in its application.
\end{abstract}

Keywords: Creative Process; Idea Generation; Ideation Game; Design Tools 


\section{Introdução}

Segundo Valjak (2016), a criatividade trata-se de uma habilidade humana básica que permite, por meio de pensamentos criativos, gerar ideias inovadoras. Esta, segundo o autor, se faz necessária ao longo do projeto de um novo produto/serviço. Nesse contexto, diversas são as definições de criatividade: Boden (2004) define como a capacidade de criar novas ideias ou artefatos; já Childs et al. (2006) define criatividade como a capacidade de imaginar ou inventar algo novo que agregue valor.

O processo criativo no design caracteriza-se pela sistematização do pensamento criativo, no qual pensamentos racionais são combinados com a imaginação, visando-se um resultado, principalmente em técnicas de grupo, em que se usa da sinergia coletiva para se gerar novas ideias (DSCHOOL, 2010). O Design Thinking, como a própria designação descreve, é uma forma de se pensar por meio do design. Segundo Dorst (2011), ele vem sendo usado como uma maneira de lidar com problemas em diferentes áreas, tratando-se, portanto, mais de uma abordagem do que um método. A ideação é uma fase do processo de design, geralmente associado ao processo de Design Thinking, que compreende a geração de diferentes ideias ou soluções para um determinado problema por meio do uso de ferramentas e técnicas.

De acordo com a Dschool (2010), a ideação pode ser útil para diferentes propósitos, como aumentar o potencial de inovação das soluções, tornar as opções de soluções mais flexíveis em termos de variedade e gerar fluência, conduzindo a equipe para além das soluções óbvias. Nesse sentido, para estimular a criatividade, uma ampla gama de técnicas e ferramentas vêm sendo criada e adaptada, dentre elas o Ideation Game. Os jogos de ideação é uma das técnica criativas na qual, de acordo com Kumar (2013), o time é engajado a gerar novos conceitos por meio de atividades no formato de jogos. $\mathrm{O}$ autor coloca ainda que os jogos engajam as pessoas a solucionarem problemas de forma mais criativa, incentivando a tomada de decisão e o pensamento estratégico. Assim, os jogos de ideação são desenvolvidos pelo grupo de forma a atender um desafio "baseado em insights, princípios e frameworks pré-definidos e centrados no usuário" (KUMAR, 2013, p. 225).

Desse modo, o presente estudo apresenta a incorporação do jogo Bingo à uma técnica de ideação, a Ideation Game. O objetivo deste estudo é testar a adaptação de um jogo clássico - o Bingo - juntamente com o método TRIZ, como uma técnica de ideação, de modo a servir de ferramenta para criar, gerar e adaptar alternativas de soluções de design para um problema proposto. Assim, torna-se o processo de ideação mais lúdico e fluído. Para este trabalho, a técnica foi aplicada em sala de aula durante uma aula da disciplina de Processos Criativos em Design, do Programa de Pós-Graduação em Design da Universidade Federal do Rio Grande do Sul (PGDesign/UFRGS). 


\section{Fundamentação Teórica}

\subsection{Processos Criativos em Design}

Segundo Dorst e Cross (2001), a criatividade no processo de design caracteriza-se pela ocorrência de eventos denominados saltos criativos, que fazem com que o designer identifique conceitos-chave ao longo do processo. Howard, Culley e Dekoninck (2008) abordam pesquisas como as de Basadur et al. (2000) e Kryssanov et al. (2001), que trazem o processo criativo como uma operação baseada em atividades, análoga ao processo de design. Um dos mais antigos modelos de processo criativo propostos é o desenvolvido por Graham Wallas nos anos 1920, composto pelas fases: preparação, incubação, iluminação e verificação (ZAVADIL, SILVA e TSCHIMMEL, 2016). Com uma proposta mais contemporânea, Rosenman e Gero (1993) sugerem quatro procedimentos, no entanto denominando as fases de: combinação, mutação, analogia e primeiros princípios.

Técnicas de ideação tendem a auxiliar os designers na geração de múltiplos conceitos durante o processo de design criativo (DALY et al., 2016). Com isso, uma variedade de técnicas e métodos criativos vêm sido desenvolvidos ao longo dos anos, tendo como objetivo auxiliar os designers a inventar novas ideias (VALJAK, 2016). Yan e Childs (2015) apontam que o princípio por trás destes métodos é a remoção de bloqueios mentais que inibem a criatividade. A diversidade de métodos criativos proporciona aos designers a oportunidade de escolha cujas características de cada técnica/ferramenta possam adequar-se a diferentes atributos de personalidade e aplicações (YAN e CHILDS, 2015).

\subsection{Técnicas de Ideação}

Segundo Dorta (2008), a ideação é uma atividade complexa e de suma importância no processo de design. Geralmente, é uma das primeiras atividades a ser executada no projeto de um novo produto/serviço, em que designers consideram múltiplas alternativas (GOLEMBEWSKI e SELBY, 2010; DALY et al., 2016). Entretanto, Liu, Bligh e Chakrabarti (2003) e Brophy (2001) apontam que esta não se restringe a uma única fase, podendo ocorrer ao longo do processo de design à medida que as ideias são executadas.

De acordo com a Dschool (2010), idear não se trata de apresentar a ideia certa, mas, sim, de gerar o maior número de possibilidades. Para a fase de ideação, podem-se utilizar diferentes técnicas e ferramentas de criação, como a TRIZ (Teoria da Resolução Inventiva de Problemas). Segundo Altshuller e Clarke (2005) e Oxford Creativity (2020), a TRIZé um método de resolução de problemas desenvolvido no final dos anos 1940 por Genrich Altshuller, com base em sua análise em milhares de patentes na extinta União Soviética. O objetivo era orientar projetistas no processo de resolução de problemas ou desenvolvimento de novos conceitos por meio de estímulos advindos de problemas inovadores. A TRIZ é composta por 40 princípios de soluções inventivas, aplicáveis em domínios distintos de um produto, e cada célula de conflito na matriz de contradição ramifica-se a um subconjunto de dois a quatro princípios (VALJAK, 2016). A Figura 1 ilustra o fluxo do método TRIZ, no qual, por meio da observação de um problema 
específico, busca-se uma solução geral de um problema existente, transformando-o novamente em uma solução específica para o problema em questão (VALJAK, 2016).

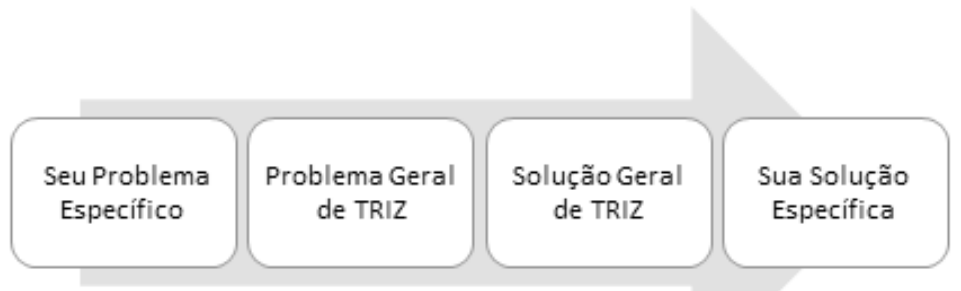

Figura 1: Fluxo do método TRIZ. Fonte: Valjak (2016)

Ainda sobre as técnicas de ideação, a própria prototipação pode ser considerada como tal, desde que se tome conhecimento acerca da diferença entre a geração de ideias e a validação destas (DSCHOOL, 2010). Durante a fase de idealização, representações, como esboços à mão livre e modelos físicos iniciais, servem aos designers como modelos para representar ou comunicar as suas intenções de design (DORTA, 2008).

\subsection{Ideation Game}

Pesquisas recentes buscaram sintetizar técnicas para obtenção de respostas criativas para problemas como forma de acelerar e desmistificar os denominados saltos criativos (DE BONO, 1985; ALTSHULLER e CLARKE, 2005; HARRIS, 2002). Segundo Zimmerling et al. (2019), nos últimos anos, técnicas de ideação vêm utilizando cada vez mais a gamificação para este fim (SCHEINER et al. 2017). A gamificação busca intencionalmente utilizar elementos de jogos para enriquecer a experiência, relacionados à atividade em questão ao contexto de jogo (SEABORN e FELS, 2015). Partindo desta premissa, o uso de elementos de design típicos de jogos como rivalidade e recompensas permite uma mudança comportamental por meio da adaptação de valores intrínsecos dos jogadores (SEABORN e FELS, 2015).

Segundo Agogué, Levillain e Hooge (2015), os Serious Games, jogos que trazem consigo técnicas para imergir o jogador em situações de gestão e aprendizagem de diversas atividades (RITTERFELD, CODY e VORDERER, 2009), vem ganhando notoriedade não só quanto ao suporte a metodologias de aprendizagem, mas também quanto ao clima de imersão e colaboração. Embora os Serious Games não tenham sido desenvolvidos especificamente para ideação, trazem em suas características a simulação da realidade, role-playing (interpretação de papéis) e suporte para colaboração, propósitos presentes nas técnicas de ideação (AGOGUÉ, LEVILLAIN e HOOGE, 2015).

Para Kumar (2013), projetar e jogar o jogo eleva os participantes para um novo nível de pensamento não-convencional, o que faz os mesmos engajarem-se de maneira informal, divertida e descontraída, tornando o processo exploratório mais valioso que os métodos diretos. Com este 
propósito, Kumar (2013) define seis passos para elaboração de um jogo com propósito de ideação (Ideation Game), sendo estes:

- Definição quanto à intenção do jogo e dados de entrada;

- Entendimento quanto o perfil dos jogadores;

- Definição do tipo de jogo que será construído e jogado;

- Conceitos chaves para construção do jogo;

- Role-play e coleta de dados;

- Compartilhamento de conceitos e discussões quanto ao refinamento e prioridades.

Assim, o propósito do jogo deve considerar a experiência desejada quanto aos seus objetivos e participantes, fazendo com que estes mantenham o foco e interesse ao longo do processo.

\section{Método}

\subsection{Objeto de Estudo}

Durante a disciplina de Processos Criativos em Design (PGDesign/UFRGS), foi proposto temáticas/problemas de projeto a serem trabalhados. Cada grupo teve por responsabilidade apresentar ferramentas e/ou técnicas em formato de seminário (parte teórica) e workshop (parte prática). A técnica proposta neste artigo representou o terceiro e último seminário relativo ao problema: "como melhorar o ambiente de estudo (espaços de circulação) dos alunos da Faculdade de Arquitetura da UFRGS", ilustrados abaixo pela Figura 2, por meio da técnica de ideação Ideation Game. Isto é, o grupo já havia obtido informações a respeito da problemática nos seminários anteriores, mediante técnicas/ferramentas, como mapa mental e painel semântico (levantamento de informações) e analogias e matriz morfológica (ideações iniciais).

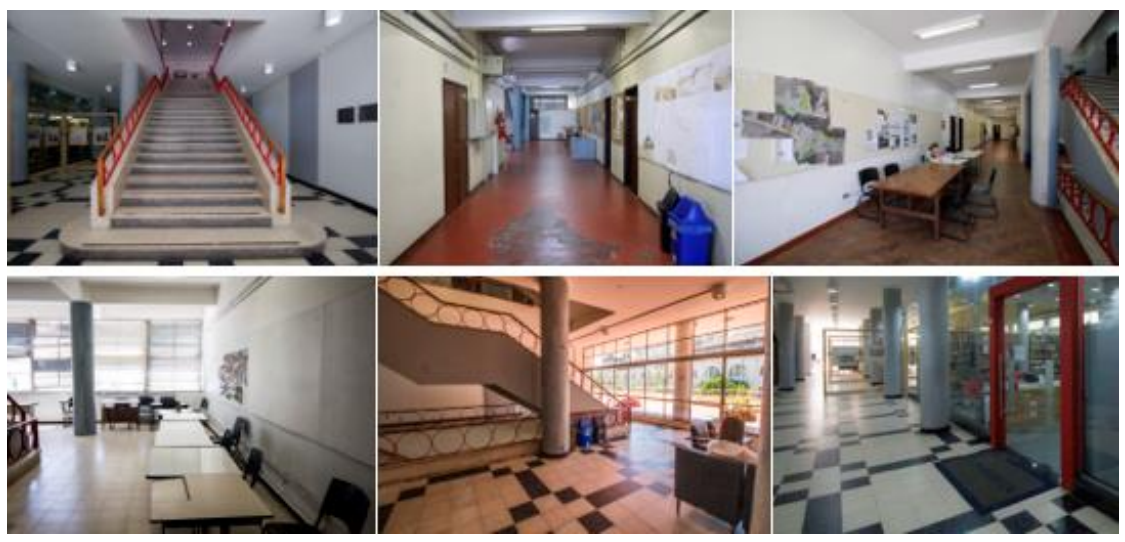

Figura 2: Espaços de circulação da Faculdade de Arquitetura da UFRGS. Fonte: Os autores (2020)

A fim de testar a adaptação do tradicional jogo de Bingo à técnica de ideação Ideation Game, somou-se o método TRIZ, de modo a servir como ferramenta geradora de inspirações e estímulos durante o desenvolvimento de um problema de design. Seguindo as proposições de Kumar (2013), 
o estudo foi segmentado em quatro sessões de ideação, seguidos de uma entrevista para fechamento do experimento.

A intenção do jogo foi propor um modelo real de produto que atenda ao objeto de estudo. A cada rodada do jogo, são sorteados números correspondentes a TRIZ que devem ser implementados ou suprimidos no design do modelo proposto. Em outras palavras, a cada número acertado na cartela, este deve corresponder a uma das 40 TRIZ de princípios inventivos extraídos do trabalho de Cardoso (2012), ou uma implementação livre por parte dos participantes. Estas devem ser analisadas e aplicadas no modelo de produto de forma direta, instigando os participantes a implementarem funções as quais não haviam sido pensadas.

Ao fim da sessão de ideação, os participantes foram entrevistados de forma semiestruturada e questionados a respeito das ideias geradas de forma retrospectiva, cam a finalidade de discutir as suas abordagens inspiradoras, compartilhando, assim, os conceitos alcançados. Desta forma, permitiu-se uma comparação entre os grupos acerca de suas estratégias para implementação das TRIZ, bem como o seu desempenho durante a sessão.

\subsection{Participantes e Condições}

Para o presente estudo, foram envolvidos 11 estudantes de áreas de formação diversas (Design, Arquitetura, Engenharia, Administração, Física) da disciplina de Processos Criativos em Design de Pós-graduação em Design da Universidade Federal do Rio Grande do Sul, sendo sete alunos do mestrado e quatro do doutorado. Os discentes foram divididos em três grupos: azul, verde e vermelho, por meio de sorteio. Dois dos grupos contaram com quatro participantes e um com três. O Quadro 1 demonstra o nível de titularidade dos estudantes por grupo.

\begin{tabular}{|l|c|c|c|}
\hline & Grupo Azul & Grupo Verde & Grupo Vermelho \\
\hline Estudantes de Mestrado & 2 & 2 & 3 \\
\hline Estudantes de Doutorado & 1 & 2 & 1 \\
\hline
\end{tabular}

Quadro 1: Relação de nível de titularidade dos estudantes por grupo. Fonte: Os autores (2020)

Como conceito chave, foi concedido para cada grupo um material específico a ser trabalhado ao longo do experimento, como: papel, tesoura, cola e fita para o grupo azul; peças sortidas de lego para o grupo verde; e massa de modelar colorida para o grupo vermelho. Todos os grupos contaram também com papéis e canetas coloridas para utilização nos detalhamentos ao longo do experimento, além de quatro cartelas de Bingo contendo quinze números aleatórios entre 1 e 90 e uma folha com a relação de número/TRIZ para guiar as implementações. 


\subsection{Procedimentos}

Com duração média de duas horas e meia, este experimento foi dividido em duas etapas: a primeira composta por quatro fases de ideação, e a segunda por uma entrevista semiestruturada, como ilustra a Figura 3. Todas as etapas ocorreram em um único local, preparado para este fim experimental.

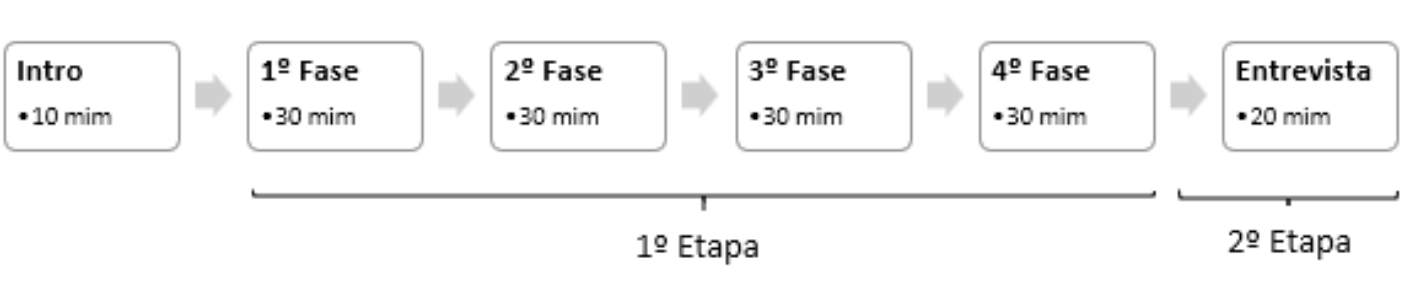

Figura 3: Condução do experimento. Fonte: Os autores (2020)

Para as fases de ideação, foram estipuladas rodadas com duração média de 30 minutos para cada uma. Como primeiro procedimento, antecedendo a primeira rodada, os participantes foram orientados a respeito das regras e andamento do jogo. Além disso, os convidados puderam escolher como referência do produto a ser desenvolvido ao longo deste experimento as ideias geradas nos seminários anteriores, por meio de mapas mentais, painéis semânticos, conceituais e visuais, desenhos de analogias e oriundos da matriz morfológica. Foi permitido também aos participantes utilizarem papéis e canetas para expressar detalhes, mecânicas e outros elementos que complementam o modelo real.

Com apoio e gerenciamento pelos autores ao longo das quatro rodadas, foi solicitado que na primeira rodada os grupos desenvolvessem um modelo base de produto, fundamentando-o nas referências e utilizando os materiais atribuídos a eles. Para as três demais rodadas, os autores sortearam um total de 30 números por rodada, por intermédio de um globo, que teve por função embaralhar as pedras com os números a serem sorteados, semelhantemente ao tradicional jogo de Bingo, como demonstra a Figura 4.

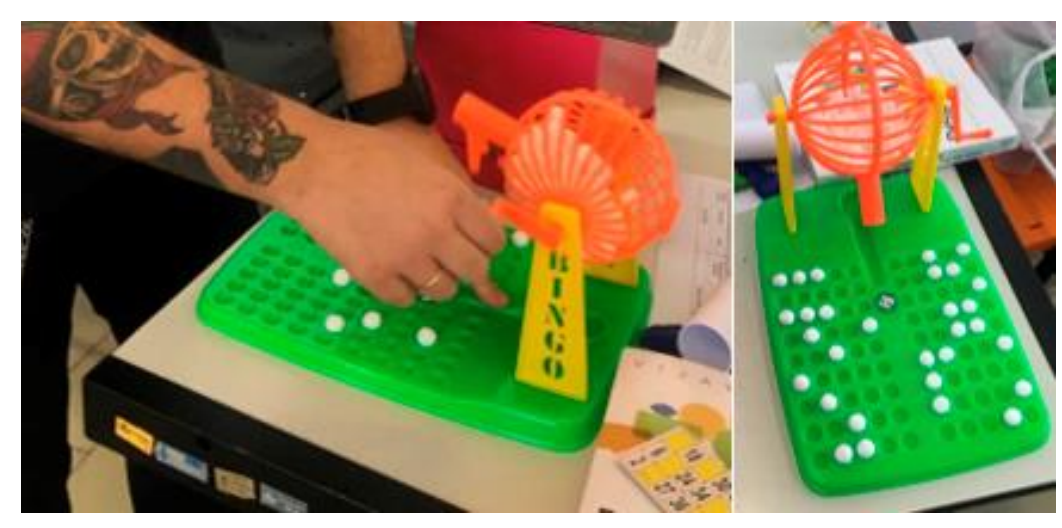

Figura 4: Sorteio dos números pelos autores. Fonte: Os autores (2020)

A cada rodada, os grupos deveriam marcar em suas cartelas os números correspondentes aos sorteados pelos autores, caso possuíssem. Ao final de cada sorteio, o grupo que preenchesse em 
sua cartela todos os números ou obtivesse o maior número de acertos, poderia escolher três de seus números para repassar a outros grupos. Com isso, ao final de cada sorteio, foi dado o tempo restante da rodada para que eles implementassem as TRIZ correspondentes aos números sorteados em suas cartelas e/ou advindos de outro grupo. O objetivo do grupo vencedor de cada rodada é dificultar o grupo adversário, fazendo com que eles implementem as TRIZ sorteadas consideradas difíceis pelo grupo. Os resultados oriundos destas quatro rodadas são aprofundados no Item 4.

\section{Resultados e Discussão}

\subsection{Uso das Triz Inventivas}

Como resultado das quatro fases de ideação, pode-se averiguar as TRIZ sorteadas por grupos bem como suas implementações. O Quadro 2 expressa detalhadamente estas informações.

\begin{tabular}{|c|c|c|}
\hline Número / TRIZ & Grupos & Solução Implementada \\
\hline $\begin{array}{l}\text { 1ou 41) Segmentação: consiste em dividir } \\
\text { um objeto em partes independentes ou } \\
\text { aumentar o grau de segmentação de um } \\
\text { objeto. }\end{array}$ & Não Sorteada & - \\
\hline \multirow{3}{*}{$\begin{array}{l}2 \text { ou 42) Extração: extrair ou separar a } \\
\text { parte ou propriedade indesejada de um } \\
\text { objeto. }\end{array}$} & Grupo Azul & Extração de pontas do móvel \\
\hline & Grupo Verde & $\begin{array}{l}\text { Extração do sistema de rodas a fim } \\
\text { de evitar acidentes }\end{array}$ \\
\hline & Grupo Vermelho & $\begin{array}{l}\text { Segmentação das poltronas em } \\
\text { duas partes }\end{array}$ \\
\hline $\begin{array}{l}3 \text { ou 43) Qualidade local: transformar uma } \\
\text { estrutura homogênea para heterogênea de } \\
\text { um objeto. Atribuir diferentes funções para } \\
\text { cada parte de um objeto. Posicionar cada } \\
\text { parte de um objeto na melhor condição para } \\
\text { sua operação }\end{array}$ & Não Sorteada & - \\
\hline \multirow{2}{*}{$\begin{array}{l}4 \text { ou 44) Assimetria: tornar o objeto } \\
\text { assimétrico ou aumentar o grau de } \\
\text { assimetria. }\end{array}$} & Grupo Azul & - \\
\hline & Grupo Verde & $\begin{array}{l}\text { Sistema de mesa e acentos } \\
\text { simétricos }\end{array}$ \\
\hline $\begin{array}{l}5 \text { ou 45) Combinação: unir objetos } \\
\text { idênticos ou similares para executar } \\
\text { operações em paralelo }\end{array}$ & Não Sorteada & - \\
\hline $\begin{array}{l}6 \text { ou } 46 \text { ) Universalidade: atribuir múltiplas } \\
\text { funções a um objeto desprezado à } \\
\text { necessidade de outro objeto para executá- } \\
\text { las. }\end{array}$ & Não Sorteada & - \\
\hline $\begin{array}{l}7 \text { ou 47) Aninhamento: colocar um objeto } \\
\text { dentro de outro objeto, do qual passe por }\end{array}$ & Não Sorteada & - \\
\hline
\end{tabular}




\begin{tabular}{|c|c|c|}
\hline sua cavidade. & & \\
\hline \multirow{2}{*}{$\begin{array}{l}8 \text { ou } 48 \text { ) Contrapeso: compensar o peso de } \\
\text { um objeto pela união com outro que } \\
\text { produza sustentação. }\end{array}$} & Grupo Azul & Porta objetos \\
\hline & Grupo Vermelho & $\begin{array}{l}\text { Parte inferior da poltrona com } \\
\text { peso maior }\end{array}$ \\
\hline \multirow{2}{*}{$\begin{array}{l}9 \text { ou 49) Compensação prévia: se uma } \\
\text { ação produz efeitos úteis e nocivos ao } \\
\text { mesmo tempo, compense previamente os } \\
\text { efeitos nocivos com uma anti-ação. }\end{array}$} & Grupo Verde & - \\
\hline & Grupo Vermelho & $\begin{array}{l}\text { Utilização da parte inferior da } \\
\text { poltrona para evitar furtos, por ela } \\
\text { ser mais pesada }\end{array}$ \\
\hline $\begin{array}{l}10 \text { ou 50) Ação prévia: realizar alterações } \\
\text { necessárias para um objeto completamente } \\
\text { ou parcialmente com antecedência. }\end{array}$ & Grupo Verde & $\begin{array}{l}\text { Sistema de mesa dobrável, sendo } \\
\text { necessário desdobrá-la } \\
\text { previamente para sua utilização }\end{array}$ \\
\hline $\begin{array}{l}11 \text { ou 51) Amortecimento ou proteção } \\
\text { prévia: compensar a confiabilidade } \\
\text { relativamente baixa de um objeto com } \\
\text { medidas de emergência preparadas com } \\
\text { antecedência. }\end{array}$ & Grupo Vermelho & $\begin{array}{l}\text { Material de preenchimento das } \\
\text { almofadas com material de aspecto } \\
\text { "flutuante" }\end{array}$ \\
\hline $\begin{array}{l}12 \text { ou 52) Equipotencialidade: alterar a } \\
\text { condição de trabalho de tal forma que não } \\
\text { seja necessária à elevação de um objeto. }\end{array}$ & Grupo Azul & - \\
\hline \multirow{2}{*}{$\begin{array}{l}13 \text { ou 53) Inversão: aplicar uma ação } \\
\text { oposta ou reversa; virar de cabeça para } \\
\text { baixo ou virar do avesso. }\end{array}$} & Grupo Verde & - \\
\hline & Grupo Vermelho & - \\
\hline $\begin{array}{l}14 \text { ou } 54 \text { Esferoidicidade: substituir } \\
\text { atributos retilíneos por curvas ou } \\
\text { propriedades esféricas. }\end{array}$ & Não Sorteada & - \\
\hline \multirow{2}{*}{$\begin{array}{l}15 \text { ou 55) Dinamicidade: fazer um estado } \\
\text { de sistema ou propriedade efêmera móvel, } \\
\text { adaptável, flexível ou mutável. }\end{array}$} & Grupo Azul & Bancos removíveis \\
\hline & Grupo Verde & $\begin{array}{l}\text { Sistema giratório na base do } \\
\text { produto, permitindo girar o } \\
\text { conjunto de mesas e assentos de } \\
\text { modo que o produto funcione de } \\
\text { forma dinâmica }\end{array}$ \\
\hline \multirow{2}{*}{$\begin{array}{l}16 \text { ou 56) Ação parcial ou excessiva: } \\
\text { quando for difícil de obter } 100 \% \text { do efeito } \\
\text { desejado, buscar a proximidade do efeito. }\end{array}$} & Grupo Azul & - \\
\hline & Grupo Verde & - \\
\hline $\begin{array}{l}17 \text { ou 57) Mudança para uma nova } \\
\text { dimensão: mudar um sistema de linear } \\
\text { para planar, de planar para tridimensional, } \\
\text { de tridimensional para unidimensional, de } \\
\text { vertical para a horizontal, da horizontal } \\
\text { para a diagonal, etc. }\end{array}$ & Não Sorteada & - \\
\hline $\begin{array}{l}18 \text { ou 58) Vibração mecânica: utilizar } \\
\text { vibração ou oscilação em um objeto. }\end{array}$ & Grupo Vermelho & $\begin{array}{l}\text { Poltronas com sistema de } \\
\text { massagem por vibração }\end{array}$ \\
\hline 19 ou 59) Ação periódica: modificar como & Não Sorteada & - \\
\hline
\end{tabular}




\begin{tabular}{|c|c|c|}
\hline $\begin{array}{l}\text { uma ação é realizada para atingir o } \\
\text { resultado esperado, de continua para } \\
\text { periódica ou em com frequência diferente. }\end{array}$ & & \\
\hline $\begin{array}{l}20 \text { ou } 60 \text { ) Continuidade de uma ação útil: } \\
\text { criar fluxos contínuos e/ou eliminar todos } \\
\text { os movimentos ociosos e intermediários } \\
\text { para aumentar a eficiência. }\end{array}$ & Não Sorteada & - \\
\hline $\begin{array}{l}21 \text { ou 61) Travessia rápida: aumentar a } \\
\text { velocidade de processos ou etapas de } \\
\text { processos possivelmente danosos. }\end{array}$ & Não Sorteada & - \\
\hline \multirow{2}{*}{$\begin{array}{l}22 \text { ou 62) Converter danos em benefícios: } \\
\text { utilizar fatores ou efeitos danosos ou } \\
\text { prejudiciais em lucro ou benefício. }\end{array}$} & Grupo Verde & $\begin{array}{l}\text { Objeto pesado, evita que seja } \\
\text { furtado }\end{array}$ \\
\hline & Grupo Vermelho & - \\
\hline $\begin{array}{l}23 \text { ou } 63 \text { ) Retroalimentação ou feedback: } \\
\text { introduzir a retroalimentação ou resposta } \\
\text { do sistema quando esta não existir ou } \\
\text { modificá-la se houver. }\end{array}$ & Não Sorteada & - \\
\hline $\begin{array}{l}24 \text { ou 64) Mediação: Mediar ou negociar, } \\
\text { um link temporário entre as partes } \\
\text { incompatíveis, funções, eventos ou } \\
\text { condições. Usar um transportador } \\
\text { intermédio, bloqueador ou processo que } \\
\text { pode ser facilmente removido. }\end{array}$ & Grupo Azul & - \\
\hline $\begin{array}{l}25 \text { ou } 65 \text { ) Autosserviço: desempenhar } \\
\text { funções suplementares (autônomas) e/ou de } \\
\text { reparo. }\end{array}$ & Não Sorteada & - \\
\hline \multirow{2}{*}{$\begin{array}{l}26 \text { ou 66) Cópia: explorar uma cópia } \\
\text { réplica ou modelo ao invés de algo muito } \\
\text { valioso. }\end{array}$} & Grupo Azul & - \\
\hline & Grupo Verde & - \\
\hline $\begin{array}{l}27 \text { ou 67) Uso de objetos descartáveis: } \\
\text { utilizar objetos mais baratos, simples ou } \\
\text { descartáveis de forma a reduzir o custo. }\end{array}$ & Não Sorteada & - \\
\hline $\begin{array}{l}28 \text { ou } 68) \text { Substituição de meios } \\
\text { mecânicos: Substitua interações } \\
\text { mecânicas, dispositivos, mecanismos e } \\
\text { sistemas com campos físicos por sistemas } \\
\text { óptico, acústico ou tátil. }\end{array}$ & Grupo Azul & - \\
\hline $\begin{array}{l}29 \text { ou 69) Utilizar pneumática ou } \\
\text { hidráulica: utilizar gás ou líquido para } \\
\text { substituir partes sólidas de um sistema. }\end{array}$ & Não Sorteada & - \\
\hline $\begin{array}{l}30 \text { ou } 70) \text { Uso de filmes e membranas } \\
\text { flexíveis: a utilização de filmes e } \\
\text { membranas flexíveis isola o objeto do } \\
\text { ambiente externo. }\end{array}$ & Grupo Azul & Membrana para difundir a luz \\
\hline $\begin{array}{l}31 \text { ou } 71 \text { ) Uso de materiais porosos: } \\
\text { utilizar materiais porosos em um sistema }\end{array}$ & Não Sorteada & - \\
\hline
\end{tabular}




\begin{tabular}{|c|c|c|}
\hline $\begin{array}{l}\text { ou, se eles já forem utilizados, preenche-los } \\
\text { com material útil. }\end{array}$ & & \\
\hline $\begin{array}{l}32 \text { ou } 72 \text { ) Mudar a cor: modificar a cor de } \\
\text { um sistema ou seu ambiente para agregar } \\
\text { valor ou detectar problemas. }\end{array}$ & Grupo Vermelho & - \\
\hline $\begin{array}{l}33 \text { ou } 73 \text { ) Homogeneidade: se dois ou } \\
\text { mais objetos ou materiais interagem entre } \\
\text { si, eles devem ser constituídos das mesmas } \\
\text { substâncias, energia ou propriedade em um } \\
\text { sistema. }\end{array}$ & Não Sorteada & - \\
\hline \multirow{2}{*}{$\begin{array}{l}34 \text { ou 74) Descarte e recuperação de } \\
\text { partes: eliminar ou modificar partes de um } \\
\text { sistema que já tenham cumprido suas } \\
\text { funções. }\end{array}$} & Grupo Azul & Régua com tomadas \\
\hline & Grupo Verde & Mesas dobráveis \\
\hline $\begin{array}{l}35 \text { ou } 75) \text { Mudança de propriedades: } \\
\text { mudar as propriedades de um objeto ou } \\
\text { sistema para acomodar um benefício útil. }\end{array}$ & Grupo Azul & Assentos infláveis \\
\hline $\begin{array}{l}36 \text { ou 76) Mudança de fase: utilizar a } \\
\text { transição de fase de um material ou } \\
\text { situação para programar um efeito ou criar } \\
\text { uma mudança no sistema. }\end{array}$ & Grupo Verde & - \\
\hline \multirow{2}{*}{$\begin{array}{l}37 \text { ou } 77) \text { Expansão térmica: utilizar } \\
\text { materiais que se expandem ou contraem } \\
\text { com calor ou frio. }\end{array}$} & Grupo Verde & - \\
\hline & Grupo Vermelho & - \\
\hline \multirow{3}{*}{$\begin{array}{l}38 \text { ou } 78 \text { ) Oxidação acelerada: substituir o } \\
\text { ar comum por ar enriquecido com oxigênio. } \\
\text { Substituir o ar enriquecido com oxigênio } \\
\text { por oxigênio puro. Usar ar ionizado ou } \\
\text { oxigênio ionizado. Usar ozônio no lugar do } \\
\text { oxigênio. }\end{array}$} & Grupo Azul & - \\
\hline & Grupo Verde & - \\
\hline & Grupo Vermelho & - \\
\hline $\begin{array}{l}39 \text { ou 79) Ambiente inerte: criar uma } \\
\text { atmosfera inerte. }\end{array}$ & Não Sorteada & - \\
\hline $\begin{array}{l}40 \text { ou } 80) \text { Uso de materiais compostos: } \\
\text { substituir materiais homogêneos por } \\
\text { compostos. }\end{array}$ & Não Sorteada & - \\
\hline \multirow[t]{3}{*}{81 a 90) Implementação Livre } & Grupo Azul & Pernas ajustáveis à altura \\
\hline & Grupo Verde & Sistema de ajuste de altura \\
\hline & Grupo Vermelho & $\begin{array}{l}\text { Bichos infláveis / Sistema de } \\
\text { armazenagem das almofadas }\end{array}$ \\
\hline
\end{tabular}

Quadro 2: Relação de TRIZ sorteadas por grupo e suas respectivas implementações. Fonte: Os autores (2020)

Devido ao curto tempo do experimento, em média 52,5\% das TRIZ sorteadas para os grupos foram implementadas. O Quadro 3 demonstra estes dados. 


\begin{tabular}{|l|l|l|}
\hline Grupo & Número de TRIZ sorteadas & Número de TRIZ implementadas \\
\hline Grupo Azul & 14 & 7 \\
\hline Grupo Verde & 14 & 7 \\
\hline Grupo Vermelho & 12 & 7 \\
\hline
\end{tabular}

Quadro 3: Implementação das TRIZ por grupo. Fonte: Os autores (2020)

Mesmo que a implementação tenha sido de cerca de 50\% dos números sorteados, cabe ressaltar que o resultado final do experimento não foi prejudicado. No que tange ao objetivo de instigar a criatividade quanto à implementação das TRIZ associadas ao Bingo, o propósito foi alcançado. Além disso, pode-se observar que todos os grupos conseguiram implementar o mesmo número de TRIZ, sendo a ordem de escolha de suas implementações priorizadas de acordo com as que apresentaram maior compatibilidade com os materiais disponíveis frente às ideias do produto em questão.

\subsection{Materiais aplicados}

A seleção dos materiais a serem utilizados neste experimento buscou estimular resultados distintos, uma vez que cada um dos grupos teve um tipo de material disponível para a ideação, proporcionando o exercício da criatividade para diferentes soluções. Os materiais selecionados para a atividade foram o papel kraft, designado ao grupo azul; peças sortidas de Lego, designadas ao grupo verde; e a massa de modelar de cores sortidas, para o grupo vermelho, assim identificados para reforçar ainda mais o caráter de jogo de ideação.

A escolha do papel kraft permite criar e prototipar as próprias peças em duas ou três dimensões, com o auxílio de dobras e encaixes, tesoura, cola e fita, e sem as restrições de modelos prontos. O uso do Lego se justifica não somente pelo caráter lúdico como pela sua modularidade, que oferece diversas peças prontas para o uso, rápida prototipação, versátil sistema de construção, além de incentivar os poderes criativos. A própria Lego já trabalha com linhas específicas, como o LEGO MINDSTORMS, resultado de uma parceria de mais de uma década entre o Media Lab do Massachusetts Institute of Technology (MIT) e o LEGO GROUP. Essa linha do Lego possibilita criar e comandar robôs por meio de programação feita pelo próprio usuário. Já a massa de modelar é amplamente utilizada para estimular a criatividade tanto em ambientes escolares quanto para adultos, inclusive associada ao trabalho de prototipação. Como ela é moldável, oferece liberdade para criar formas mais orgânicas, assemelhando-se às técnicas artísticas de modelagem como cerâmica. A Figura 5 demonstra o processo de geração de ideias dos grupos a partir da utilização dos materiais propostos, frente às TRIZ sorteadas. 


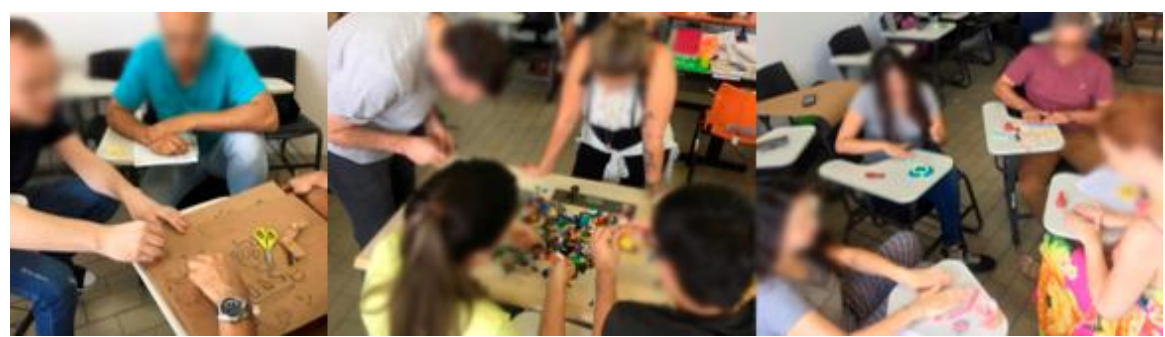

Figura 5: Grupos Azul, Verde e Vermelho durante o processo de criação. Fonte: Os autores (2020)

\subsection{Alternativas}

\subsubsection{Grupo Azul}

Denominado "Scops", a alternativa de produto gerado pelo Grupo Azul é expressa em seu nome, sua forma e sua função. Um objeto para descanso e estudo, inspirado em um escorpião, dispõe de formas orgânicas e ajuste de altura, facilitando a aproximação das pessoas ao longo da mesa. Conta com assentos infláveis, os quais proporcionam conforto quando utilizados, e economia de espaço quando armazenados. Uma membrana articulável remete à cauda do animal, destinada a difundir a iluminação no ambiente durante o processo de estudo. Tomadas alimentam de energia o produto. A Figura 6 ilustra os resultados dos modelos gerados pelo grupo.

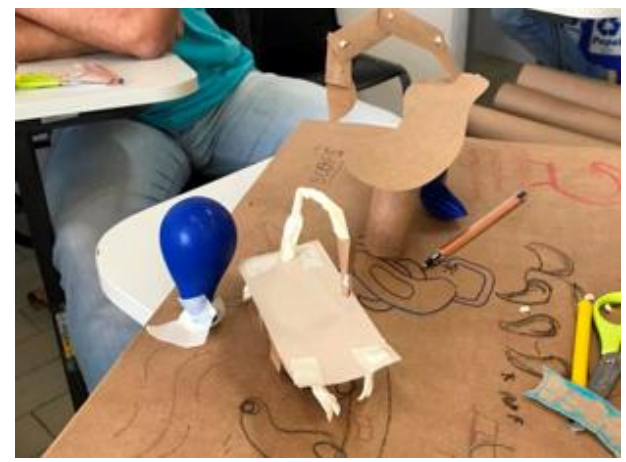

Figura 6: Resultado do jogo de ideação aplicado pelo Grupo Azul. Fonte: Os autores (2020)

\subsubsection{Grupo Verde}

O "Móbi", como denominado pelo Grupo Verde, trata-se de um modelo de produto com vista à versatilidade. Possui um conjunto de mesa e cadeiras articulados de forma simétrica, permitindo que o usuário interaja com o sistema dobrável de mesas e cadeiras conforme sua necessidade. Possui um sistema de controle de altura e rotação na base, permitindo girar o conjunto de mesas e assentos de modo que o produto funcione de forma dinâmica entre seus usuários. A Figura 7 ilustra os resultados dos modelos gerados pelo grupo. 


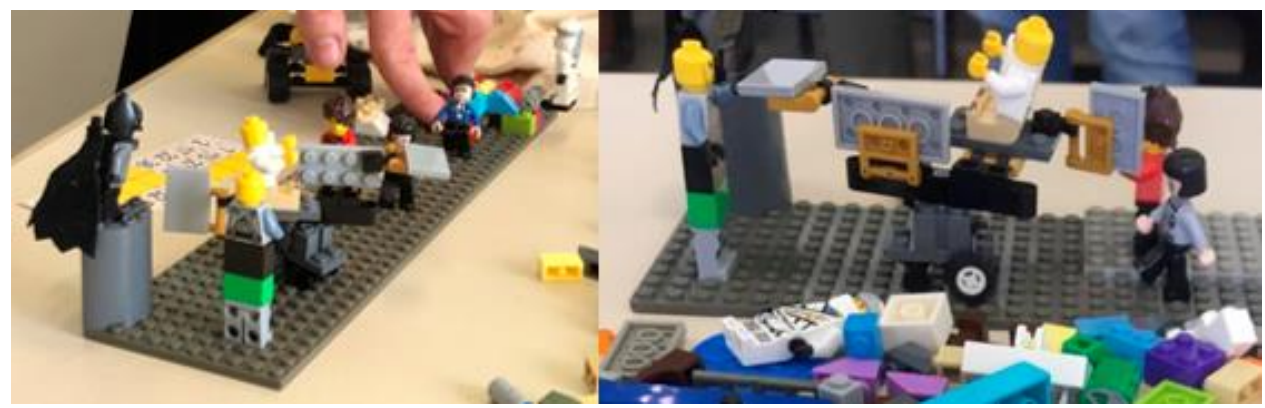

Figura 7: Resultado do jogo de ideação aplicado pelo Grupo Verde. Fonte: Os autores (2020)

\subsubsection{Grupo Vermelho}

Denominado "Berry", a alternativa de produto gerado pelo Grupo Vermelho visa o conforto e lazer dos alunos nos intervalos de aula, para estudar ou relaxar. Bastante lúdico, trata-se de um conjunto de poltronas coloridas em forma de cobras, compostas por materiais densos e macios, que expressam a sensação de flutuação. Estas também contam com um sistema de massagem por vibração e almofadas infláveis em forma de bichos para serem utilizadas como travesseiros.

Compõem o conjunto desta alternativa, armários e gaveteiros para armazenamento, ampliando o espaço de circulação do ambiente quando não utilizadas. A Figura 8 ilustra os resultados dos modelos gerados pelo grupo.

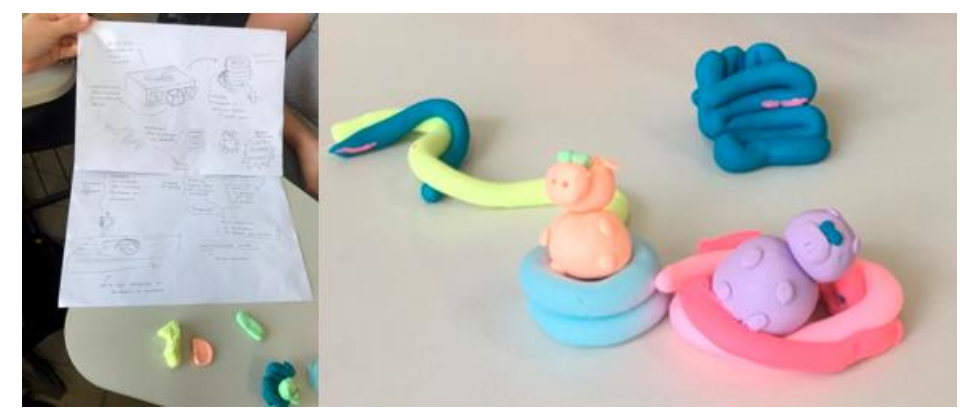

Figura 8: Resultado do jogo de ideação aplicado pelo Grupo Vermelho. Fonte: Os autores (2020)

Durante o experimento, pôde-se observar, e mais adiante na discussão no grande grupo, que: o papel kraft, tesoura e fita mostraram-se complexos no início, por não apresentarem um ponto de partida, mas ao longo do experimento abriu a mente do grupo, permitindo que eles criassem literalmente qualquer produto, simplesmente recortando, colando e encaixando. Ficou consolidado que o Lego reforçou a modularização e a utilização de componentes prontos. Já a massa de modelar, por sua vez, instigou o grupo a produzir um objeto mais orgânico e maleável, fazendo com que ideias mais complexas fossem desenhadas e detalhadas no papel. Como era esperado, os diferentes materiais suscitaram diferentes encaminhamentos. 


\section{Considerações Finais}

A partir deste experimento, foi possível compreender, sob o conjunto de ideias e conceitos gerados por cada grupo, o impacto da inspiração dos participantes por meio das abordagens trabalhadas ao longo do processo de design. Como esperado, os resultados dos produtos gerados tiveram relação estrita com os materiais propostos. O Grupo Verde, o qual dispunha de Legos para implementar suas ideias, imaginou no início que seria fácil realizar a atividade, porém encontraram dificuldades ao longo do processo, onde as peças não deram liberdade de expressar formas, escalas ou detalhes com exatidão. Em contraste com o Grupo Azul, que desde o início da ação não possuía ponto de partida como forma de inspiração, mas que, ao longo do experimento pôde gerar alternativas de forma simples e detalhada sem dificuldades. O Grupo Vermelho, que contava com a massa de modelar, foi estimulado a criar produtos com formas orgânicas e fluídas, o que leva a reflexão de que o tipo de material que se tem disponível influencia diretamente na natureza da solução que vai ser gerada. Outro ponto interessante foi a união do pensamento abstrato e criativo com o sistemático, expresso nos modelos gerado pelos grupos durante a fase de ideação. Os grupos demonstraram estar sempre focados nas funcionalidades que pudessem vir a ser executadas no produto real, no entanto não limitaram o processo criativo em torno destas.

O Bingo adaptado ao processo criativo por meio de um jogo de ideação e aliado ao método TRIZ teve um resultado interessante: impeliu os grupos a realizarem as alterações propostas pelas TRIZ, que caíram de modo aleatório durante as rodadas do Bingo, e gerou competitividade acerca do preenchimento das cartelas, de modo a "prejudicar" os demais grupos rivais. Dessa maneira, fez com o que os grupos tivessem que pensar fora da caixa para realizarem os ajustes. Assim, auxiliou-se no estímulo da criatividade na busca de soluções para as alternativas de projeto, principalmente quando os grupos já consideravam ter chegado a uma solução ótima, o que faz um paralelo com as situações reais de projeto. Como aplicações futuras ou adaptações deste experimento, sugere-se que haja maior duração, em virtude da complexidade de implementação de algumas das TRIZ sorteadas, bem como a inserção de novos desafios e recompensas, o que poderá potencializar ainda mais o caráter de jogo para a ideação.

\section{Referências}

AGOGUÉ, M.; LEVILLAIN, K.; HOOGE, S. Gamification of creativity: exploring the usefulness of serious games for ideation. Creativity and Innovation Management, v. 24, n. 3, p. 415-429, 2015.

BASADUR, M.; PRINGLE, P.; SPERANZINI, G.; BACOT, M. Collaborative problem solving through creativity in problem definition: expanding the pie. Creativity and Innovation Mangement, v. 9, p. 54-76, 2000.

BODEN, A. M. The creative mind: Myths and mechanisms. 2. ed. London: Routledge, 2004.

BROPHY, D. R. Comparing the attributes, activities, and performance of divergent, convergent, and combination thinkers. Creativity Research Journal, v. 13, n. 3-4, p. 439$455,2001$. 
CARDOSO, A. G. Proposta de jogo para a solução de problemas não estruturados com a utilização de técnicas criativas. Dissertação (Mestrado em Design) - Programa de PósGraduação em Design, Universidade Federal do Rio Grande do Sul, Rio Grande do Sul, 2012.

CHILDS, P. R. N.; HAMILTON, T.; MORRIS, R. D.; JOHNSTON, G. Centre for technology enabled creativity, Engineering And Product Design Education Conference, Salzburg: Austria, 2006.

DALY, S.; COLLEEN, M. S.; SEDA, Y.; RICHARD, G. Comparing ideation techniques for beginning designers. Journal of Mechanical Design, v. 138, p. 101108-1 101108-12, 2016.

DE BONO, E. Six thinking hats. London: Penguin Books, 1985.

DORST, K. The core of 'design thinking' and its application. Design Studies, v. 32, p. 521 $532,2011$.

DORST, K.; CROSS, N. Creativity in the design process: co-evolution of problem-solution. Design Studies, v. 22, p. 425-437, 2001.

DORTA, T. Design flow and ideation. International Journal of Architectural Computing, v. 6, n. 3, p. 299-316, 2008.

DSCHOOL. An Introduction to Design Thinking: PROCESS GUIDE, 2010. Disponível em: $\quad<$ https://dschool-old.stanford.edu/sandbox/groups/designresources/wiki/36873/ attachments/74b3d/ModeGuideBOOTCAMP2010L.pdf>. Acesso em: 10 de fevereiro 2020.

GOLEMBEWSKI, M.; MARK, S. Ideation decks: a card-based design ideation tool. Proceedings of the Conference on Designing Interactive Systems, Aarhus: Dinamarca, 2010.

HARRIS, R. Creative Thinking Techniques. Virtual Salt, 2002. Disponível em: <http://virtualsalt.com/crebook2.htm> Acesso em: 28 de janeiro 2019.

HOWARD, J. T.; CULLEY, J. S.; DEKONINCK, E. Describing the creative design process by the integration of engineering design and cognitive psychology literature. Design Studies, v. 29 , p. $160-180,2008$.

KRYSSANOV, V. V.; TAMAKI, H.; KITAMURA, S. Understanding design fundamentals: How synthesis and analysis drive creativity, resulting in emergence. Artificial Intelligence in Engineering, v. 15, p. 329-342, 2001.

KUMAR, V. 101 design methods: a structured approach for driving innovation in your organization. New Jersey: John Wiley \& Sons, 2013.

ALTSHULLER, G.; CLARKE, D. W. 40 Principles: TRIZ keys to Innovation. Worcester: Techinal Innovation Center, Inc, 2005.

LIU, Y. C.; BLIGH, T.; CHAKRABARTI, A. Towards an 'ideal' approach for concept generation. Design Studies, v. 24, n. 4, p. 341-355, 2003.

OXFORD CREATIVITY, 2020. Disponível em: <https://www.triz.co.uk/> Acesso em: $10 \mathrm{de}$ fevereiro 2020.

RITTERFELD, U.; CODY, M.; VORDERER, P. Serious games: Mechanisms and effects. London: Routledge, 2009. 
ROSENMAN, M. A.; GERO, S. J. Creativity in design using a design prototype approach. Computer Science, 1993.

SEABORN, K.; FELS, D. I. Gamification in theory and action: A survey. International Journal of Human-Computer Studies, v. 74, p. 14-31, 2015.

SCHEINER, C.; HAAS, P.; BRETSCHNEIDER, U.; BLOHM, I.; LEIMEISTER, J. M. Obstacles and challenges in the use of gamification for virtual idea communities. In S. Stieglitz, C. Lattemann, S. Robra-Bissantz, R. Zarnekow, \& T. Brockmann (Eds.). Gamification: Using game elements in serious contexts, p. 65-76, Cham: Springer International Publishing, 2017.

VALJAK, F. Creativity in the engineering design process. Journal Brodogradnja (Shipbuilding) Ethics and Faculty of Mechanical Engineering and Naval Architecture, Zagreb: Croatia, 2016.

YAN, Y.; CHILDS, P. R. N. Creativity tool selection for design engineers in idea generation. Proceedings of the 20th International Conference on Engineering Design (ICED), v. 8, p. 1-12, Milan: Italy, 2015.

ZAVADIL, P.; SILVA, R.; TSCHIMMEL, K. Modelo teórico do pensamento e processo criativo em indivíduos e em grupos de design. Design \& Tecnologia, v. 6, n.12, p. 1-20, 2016.

ZIMMERLING, E.; HÖLLIG, C. E.; SANDNER, P. G.; WELPE, I. M. Exploring the influence of common game elements on ideation output and motivation. Journal of Business Research, v. 94, p. 302-312, 2019.

\section{Sobre os autores}

\section{Jason Scalco Piloti}

Graduado em Tecnologias Digitais pela Universidade de Caxias do Sul (2015), especialista em Jogos Digitais pela Faculdade Unyleya do Rio de Janeiro (2017) e mestrando em Design pelo Programa de Pós-Graduação em Design da Universidade Federal do Rio Grande do Sul. jason.piloti@ufrgs.br

\section{Camila Vieira Ghisleni}

Graduada em Design de Produto pela Universidade Federal do Rio Grande do Sul (2017) e mestranda em Design pelo Programa de Pós-Graduação em Design da mesma Universidade (2019-2020).

camila.ghisleni@ufrgs.br

\section{Fabiano Scherer}

Graduado em Arquitetura e Urbanismo (1999), mestre em Planejamento Urbano e Regional (2002) e Doutor em Design (2017), todos pela Universidade Federal do Rio Grade do Sul. Professor Adjunto nos Cursos de Design (Design Visual e Design de Produto) da Universidade Federal do Rio Grande do Sul. Professor colaborador no Programa de Pós-Graduação em Design - PGDESIGN/UFRGS.

fabiano.scherer@ufrgs.br 